\title{
Strength Recovery in a High-Strength Steel During Multiple Weld Thermal Simulations
}

\author{
XINGHUA YU, JEREMY L. CARON, S.S. BABU, JOHN C. LIPPOLD, DIETER ISHEIM, \\ and DAVID N. SEIDMAN
}

\begin{abstract}
BlastAlloy 160 (BA160) is a low-carbon martensitic steel strengthened by copper and $\mathrm{M}_{2} \mathrm{C}$ precipitates. Heat-affected zone (HAZ) microstructure evaluation of BA160 exhibited softening in samples subjected to the coarse-grained HAZ thermal simulations of this steel. This softening is partially attributed to dissolution of copper precipitates and metal carbides. After subjecting these coarse-grained HAZs to a second weld thermal cycle below the $A_{c 1}$ temperature (at which austenite begins to form on heating), recovery of strength was observed. Atom-probe tomography and microhardness analyses correlated this strength recovery to re-precipitation of copper precipitates and metal carbides. A continuum model is proposed to rationalize strengthening and softening in the HAZ regions of BlastAlloy 160.
\end{abstract}

DOI: $10.1007 / \mathrm{s} 11661-011-0707-y$

(c) The Minerals, Metals \& Materials Society and ASM International 2011

\section{INTRODUCTION}

To meet the rigorous requirements for the United States Navy hull and deck application, a blast resistant steel, BlastAlloy 160 (BA160), was developed at Northwestern University. ${ }^{[1,2]} \mathrm{BA} 160$ is a low carbon martensitic steel additionally strengthened primarily by nanometersized $\mathrm{Cu}$-rich precipitates and $\mathrm{M}_{2} \mathrm{C}$ precipitates (where $\mathrm{M}=\mathrm{Cr}$, Mo, and $\mathrm{V})$. The yield strength of BA160 is $160 \mathrm{ksi}(1104 \mathrm{MPa})$. In addition to high strength, very good room-temperature Charpy impact toughness [176 J $(130 \mathrm{ft}-\mathrm{lb})]$ was achieved through precipitation of Ni-stabilized austenite within a martensitic matrix. The aim of BA160 development is to replace currently certified high-strength low-alloy (HSLA) steels used in surface ship structure. Typical shipyard welding procedures include gas metal arc welding (GMAW), submerged arc welding (SAW), shielded metal arc welding (SMAW), and flux cored arc welding (FCAW) ${ }^{[3]}$ These welding procedures will also be used for deploying BA160. To employ BA160 in ship building applications, it is important to understand its weldability, which is related to, among other factors, the complex solid-to-solid phase transformations that occur in heat-affected zone (HAZ) regions as a function of initial microstructure, heating rate, peak temperature $\left(T_{P}\right)$, and cooling rate.

XINGHUA YU, Graduate Student, S.S. BABU, Associate Professor, and JOHN C. LIPPOLD, Professor, are with the Department of Materials Science and Engineering, The Ohio State University, Columbus, OH 43221. Contact e-mail: babu.13@osu.edu JEREMY L. CARON, formerly Graduate Student, with the Department of Materials Science and Engineering, The Ohio State University, is now a Welding Metallurgist, with the Research and Technology Group, Haynes International, Inc., 1020 West Park Avenue, Kokomo, IN 46904. DIETER ISHEIM, Research Assistant Professor, and DAVID N. SEIDMAN, Professor, are with the Department of Materials Science and Engineering, Northwestern University, Evanston, IL 60208.

Manuscript submitted November 22, 2010.

Article published online April 27, 2011
There are many testing methodologies available to determine the weldability of structural materials and selection of appropriate tests depends on the material. ${ }^{[4]}$ Although weldability tests are not often routinely used when optimizing mechanical properties such as tensile strength and fracture toughness during alloy development, they are of great importance during weld procedure development to ensure proper deployment in service. Weldability testing techniques, including the HAZ thermal simulations, hot ductility testing, and reheat cracking testing, were employed to evaluate the weldability of BA160. ${ }^{[3]}$ For steels, there are four distinct $\mathrm{HAZ}$ regions depending upon the peak temperature in a given weld thermal cycle. (1) In subcritical HAZ regions (SCHAZ; $T_{P}<A_{c 1}$ ), no detectable transformation of ferrite to austenite occurs. (2) In the intercritical HAZ (ICHAZ), partial transformation of ferrite to austenite occurs because the peak temperature is between $A_{c 1}$ and $A_{c 3}$. (3) In the fine-grained HAZ (FGHAZ), the samples are heated to a temperature slightly above the $A_{c 3}$ temperature, after complete austenitization. (4) In the coarse-grained HAZ (CGHAZ), the sample in the austenite state is heated to a peak temperature significantly above the $A_{c 3}$. Prior research on four HAZ regions of BA160 steels, using a GLEEBLE* NY.

*GLEEBLE is a trademark of Dynamic Systems Inc., Poestenkill,

thermomechanical simulator, showed no strength change in the SCHAZ, some hardening in the ICHAZ, and softening in both the FGHAZ and CGHAZ. Atomprobe tomography (APT) characterization and strengthening analyses correlated the softening to the dissolution of $\mathrm{Cu}$ precipitates and carbides. ${ }^{[6]}$ To validate the preceding thermal simulations, gas tungsten arc (GTA) spot welds were made on BA160 samples. ${ }^{[5]}$ Vickers microhardness traverse across spot weld HAZs showed a 
Table I. Chemical Composition of the BA160

\begin{tabular}{lccccccrrr}
\hline Element & $\mathrm{C}$ & $\mathrm{Si}$ & $\mathrm{Mn}$ & $\mathrm{Cu}$ & $\mathrm{Ni}$ & $\mathrm{Cr}$ & $\mathrm{Mo}$ & $\mathrm{Ti}$ & $\mathrm{Fe}$ \\
\hline Wt pct & 0.059 & 0.015 & 0.001 & 3.390 & 6.800 & 1.900 & 0.610 & 0.016 & balance \\
At pct & 0.277 & 0.030 & 0.001 & 3.005 & 6.527 & 2.058 & 0.358 & 0.019 & balance \\
\hline
\end{tabular}

Table II. Aging Treatment Procedure for BA160 Steel

\begin{tabular}{lcll}
\hline Step & $\begin{array}{c}\text { Temperature } \\
{\left[\mathrm{K}\left({ }^{\circ} \mathrm{C}\right)\right]}\end{array}$ & Duration & $\begin{array}{c}\text { Poststep } \\
\text { Procedure }\end{array}$ \\
\hline $\begin{array}{l}\text { 1. Austenitization } \\
\text { 2. Liquid } \\
\text { nitrogen hold }\end{array}$ & $1173(900)$ & $1 \mathrm{~h}$ & $\begin{array}{l}\text { water quench } \\
\text { air warm } \\
\text { to room } \\
\text { temperature }\end{array}$ \\
$\begin{array}{l}\text { 3. Tempering } \\
\text { 4. Tempering }\end{array}$ & $823(550)$ & $30 \mathrm{~min}$ & $\begin{array}{l}\text { water quench } \\
\text { air cool } \\
\text { to room } \\
\end{array}$ \\
& & $5 \mathrm{hin}$ & temperature \\
\hline
\end{tabular}

similar phenomenon as that observed from GLEEBLE samples. Softening is shown close to the fusion line (i.e., CGHAZ) and hardening is observed in the ICHAZ. These results confirmed the presence of four distinct $\mathrm{HAZ}$ regions in the spot welds.

Based on the preceding results, thermal simulations were considered to be an effective tool to evaluate the $\mathrm{HAZ}$ regions of BA160. The fusion zone of GTA spot welds contained cellular/dendritic solidification substructure with an average hardness of $364 \mathrm{HV}$. Since both microstructure and hardness are not favorable in the fusion zone, consumables for BA160 have to be designed in the future. The focus of the current article is to develop methods to mitigate the softening in the HAZ region.

It is conceivable that postweld heat treatment (PWHT) could reinstate strength in the HAZ. For example, autogenous spot welds in the BA160 sample were postweld heat treated at $823 \mathrm{~K}\left(550{ }^{\circ} \mathrm{C}\right)$ for 30 minutes or $723 \mathrm{~K}\left(450{ }^{\circ} \mathrm{C}\right)$ for 5 hours. ${ }^{[5]}$ Strength recovery was observed in the fusion zone and HAZ. The observed strength increase was assumed to be the result of reprecipitation during the PWHT. The PWHT is not feasible for naval applications due to the size or complexity of the structures that are welded. Alternatively, strength recovery in the HAZ (or weld metal) could be achieved by designing an appropriate multipass welding procedure that leads to a similar extent of re-precipitation during PWHT. Most of the HSLA structural steel plates currently used in shipyards are in the range of 6 to $30 \mathrm{~mm}$ (0.25 to 1.25 in.) with yield strength from 448 to $689 \mathrm{MPa}$ (65 to $100 \mathrm{ksi}$ ). The thickness of heavier gage plate could be as high as $83 \mathrm{~mm}$ (3.25 in.). Though the plate thickness of BA160 will be reduced due to the high yield strength, the envisioned thickness for naval applications $(>6 \mathrm{~mm})$ is still too high for single pass welding. As a result, multipass welding is required for most applications.

For some HAZ regions (CGHAZ and FGHAZ), the first thermal cycle with high peak temperature $\left(>A_{c 3}\right)$ causes the dissolution of precipitates. Subsequent thermal cycles with low peak temperatures (773 K to $923 \mathrm{~K}$ $\left(500{ }^{\circ} \mathrm{C}\right.$ to $\left.650{ }^{\circ} \mathrm{C}\right)$ ) may trigger re-precipitation. It is

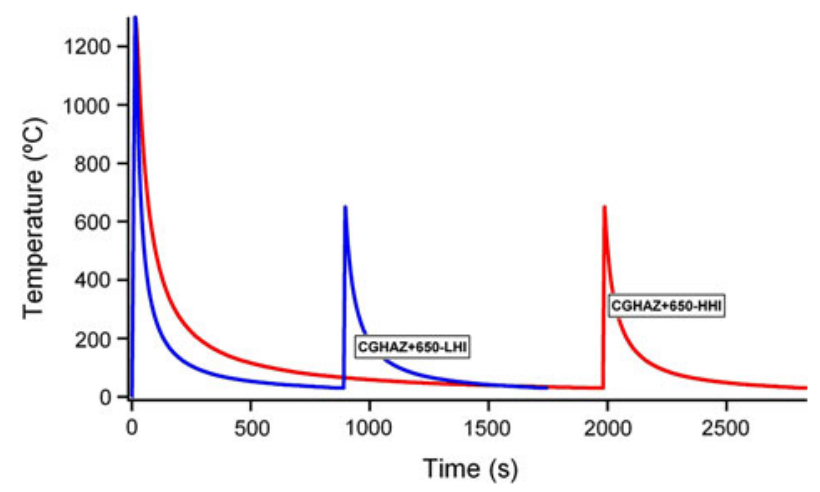

Fig. 1-Thermal profile of simulated double thermal cycle HAZ.

realized that the thermal history of multipass HAZ is complex and depends on many variables, such as plate thickness, welding procedure, and field condition. The current article only focuses on validation of the hypothesis of re-precipitation and strength recovery during the second thermal cycle in multipass welding. Thermal simulations and microstructural characterizations are used to prove the hypothesis. In addition, an appropriate strengthening model is used to rationalize the results.

\section{EXPERIMENTAL}

The BA160 experimental material was received in the form of 35-mm-diameter bar stock from QuesTek Innovations LLC (Evanston, IL). The chemical composition and heat treatment procedure for BA160 are listed in Tables I and II. To investigate the multipass HAZ microstructural evolution, thermal-cycle simulations representative of the various $\mathrm{HAZ}$ regions were performed. For actual welding conditions, the thermal history is complicated. The thermal profile for a specific location may contain several thermal cycles, depending on the number of passes. Current research pertains to only re-precipitation during the second thermal cycle with a peak temperature lower than $A_{c 1}$. As a result, four single-pass and simplified multipass HAZ regions are selected (Figure 1): (1) CGHAZ with high heat input, (2) CGHAZ + $923 \mathrm{~K}\left(650^{\circ} \mathrm{C}\right)$ reheat with high heat input, (3) CGHAZ with low heat input, and (4) CGHAZ $+923 \mathrm{~K}\left(650^{\circ} \mathrm{C}\right)$ reheat with low heat input. The $\Delta t_{8 / 5}$ (time to cool from $1073 \mathrm{~K}$ to $773 \mathrm{~K}\left(800{ }^{\circ} \mathrm{C}\right.$ to $500{ }^{\circ} \mathrm{C}$ )) was approximately 45 seconds for high heat input and 15 seconds for low heat input. The thermal cycle simulations were performed with a GLEEBLE 3800 thermomechanical simulator using solid cylindrical samples of $5 \mathrm{~mm}$ in diameter and $101.6 \mathrm{~mm}$ in length. The sample temperature was controlled with a type-K 
thermocouple, which was percussion welded at the midsection of the sample. The samples were heated to the peak temperature at a rate of $100{ }^{\circ} \mathrm{C} \mathrm{s}^{-1}$. The simulations were conducted with the test chamber evacuated to a pressure of $1.3 \times 10^{-4} \mathrm{~Pa}$ to limit surface oxidation and thermocouple detachment. Phase transformation strains were measured using a diametrical dilatometer.

The microhardness of the simulated HAZ regions was determined using a LECO** M-400-H1 microhardness-

**LECO is a trademark of LECO Corporation, St. Joseph, MI.

testing machine employing a $9.81 \mathrm{~N}$ (1 kgf) load, in accordance with ASTM Designation E-384-08 ${ }^{[7]}$ Time of load is 10 seconds. Specimens used for the microhardness testing and microstructure characterization were taken from a single test sample to ensure consistent results.

For APT samples, coupons $\left(0.3 \times 6 \times 6 \mathrm{~mm}^{3}\right)$ were cut from the center of the Gleeble specimens using a LECO VC-50 precision diamond saw. APT tip blanks $\left(0.3 \times 0.3 \times 6 \mathrm{~mm}^{3}\right)$ were cut from the coupons and electropolished using a two-step method. ${ }^{[8]}$ Initial electropolishing was performed with a solution of $10 \mathrm{vol}$ pct perchloric acid in acetic acid at 10 to $25 \mathrm{Vdc}$ at room temperature. This was followed by a manually controlled pulsed final-polishing step using a solution of 2 vol pet perchloric acid in butoxyethanol at 10 to $25 \mathrm{Vdc}$ at room temperature, producing a tip with a radius of $<50 \mathrm{~nm}$. The APT data were collected using the Cameca local-electrode atom-probe (LEAP) ${ }^{\dagger}$

${ }^{\dagger}$ LEAP and Cameca are trademarks of CAMECA Instruments, Inc., Madison, WI

tomograph at the Northwestern University Center for Atom-Probe Tomography (NUCAPT, Evanston, IL). The data were acquired at a specimen temperature in the range of 75 to $85 \mathrm{~K}$ under ultrahigh vacuum conditions of approximately $1.0 \times 10^{-8} \mathrm{~Pa}$. Short-duration laser pulses $\left(50 \mathrm{pJ}\right.$ pulse $\left.{ }^{-1}\right)$ are used to induce evaporation of ions at a pulse repetition rate of $5 \times 10^{5} \mathrm{~Hz}$ and a target evaporation rate (ions pulse ${ }^{-1}$ ) of 0.5 to 1 pct. The maximum dc voltage employed was $12 \mathrm{kV}$. Then, the acquired atomic position data are calibrated and three-dimensional reconstruction is created using Cameca’s IVAS $\$$ program.

\#IVAS is a trademark of CAMECA Instruments, Inc., Madison, WI.

To characterize the martensite matrix in BA160, a PHILIPS $^{\S}$ ESEM FEG-30 scanning electron micro-

${ }^{\S}$ PHILIPS is a trademark of FEI Company, Hillsboro, OR.

scope equipped with an electron backscatter diffraction

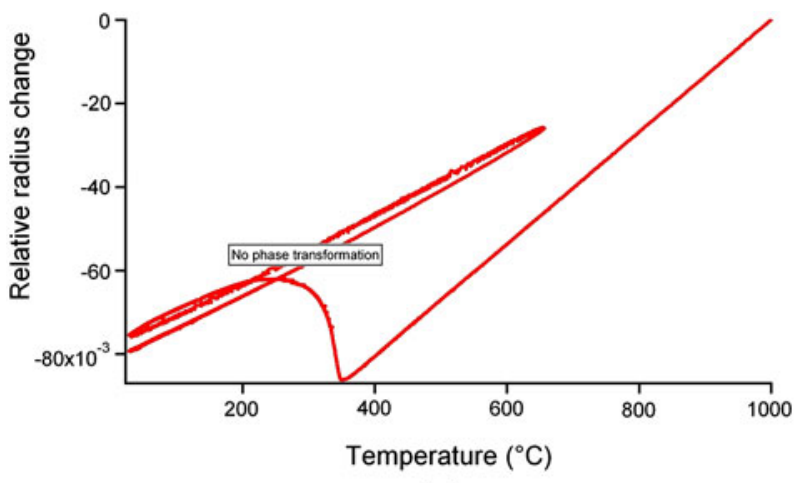

(a)

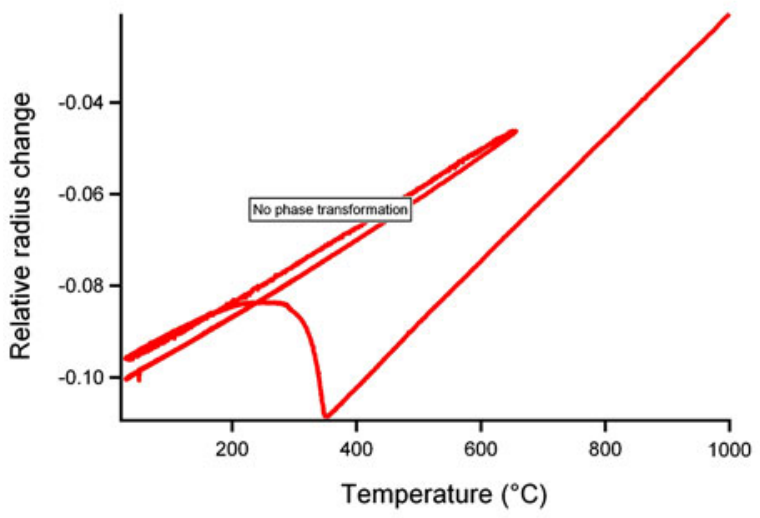

(b)

Fig. 2-Relative sample radius change and temperature trace during (a) coarse-grained HAZ +650 with high heat-input and $(b)$ coarsegrained HAZ +650 with low heat-input thermal cycles from dilatometry experiment.

(EBSD) camera was used, whose accelerating voltage is $20 \mathrm{kV}$ and spot diameter is $5 \mathrm{~nm}$, with a scanning step size of $0.1 \mu \mathrm{m}$. EBSD maps were analyzed using OIM ${ }^{\S \S}$

${ }^{\S} \mathrm{OIM}$ is a trademark of EDAX, Mahwah, NJ.

Analysis Software.

\section{RESULTS}

\section{A. GLEEBLE Simulation and Microhardness Measurement}

The experimentally measured thermal profiles from both high heat-input and low heat-input thermal cycles are shown in Figure 1. The samples were allowed to cool to room temperature from $1573 \mathrm{~K}\left(1300{ }^{\circ} \mathrm{C}\right)$ during the initial HAZ thermal cycle, prior to reheating to a peak temperature of $923 \mathrm{~K}\left(650{ }^{\circ} \mathrm{C}\right)$. The measured dilatation data during cooling from $1573 \mathrm{~K}\left(1300{ }^{\circ} \mathrm{C}\right)$ to room temperature, heating to $923 \mathrm{~K}\left(650^{\circ} \mathrm{C}\right)$ from room temperature, and cooling from $923 \mathrm{~K}\left(650^{\circ} \mathrm{C}\right)$ to room temperature are presented in Figure 2. On cooling, data for both low (Figure 2(a)) and high heat-input (Figure 2(b)) conditions show the martensite start 
Table III. Microhardness of As-Received Materials and Different HAZ Regions (Average Hardness of 10 Measurements)

\begin{tabular}{lccccc}
\hline Condition & $\begin{array}{c}\text { As- } \\
\text { Received }\end{array}$ & $\begin{array}{c}\text { CGHAZ High } \\
\text { Heat Input }\end{array}$ & $\begin{array}{c}\text { CGHAZ + 650 High } \\
\text { Heat Input }\end{array}$ & $\begin{array}{c}\text { CGHAZ Low } \\
\text { Heat Input }\end{array}$ & $\begin{array}{c}\text { CGHAZ + 650 } \\
\text { Low Heat Input }\end{array}$ \\
\hline Vickers microhardness & 402 & 340 & 405 & 351 & 404 \\
\hline
\end{tabular}

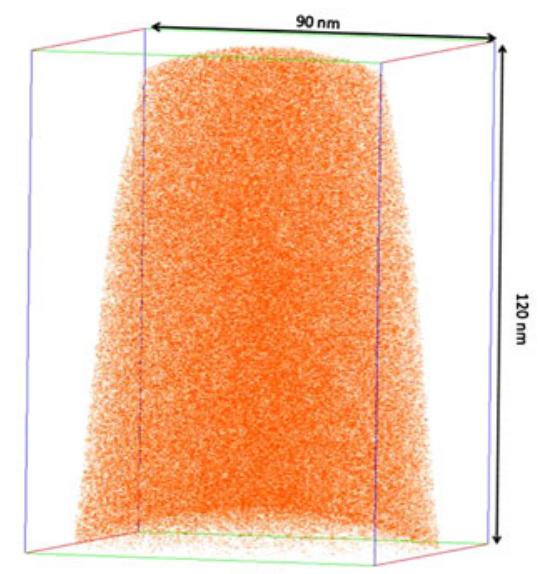

(a)

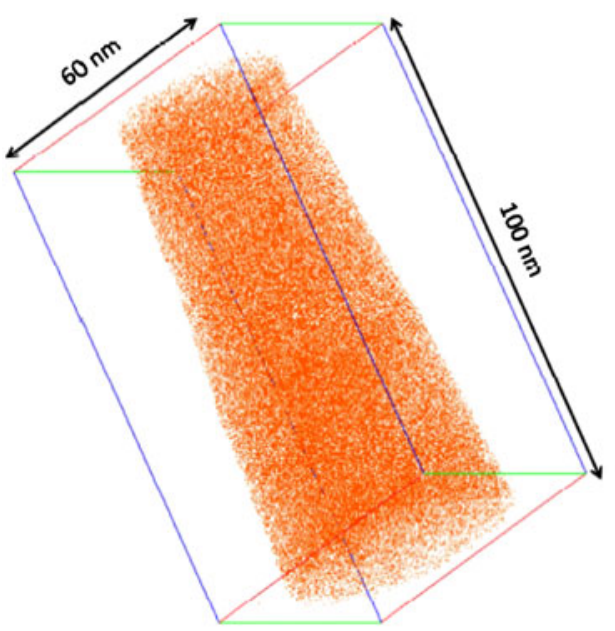

(c)

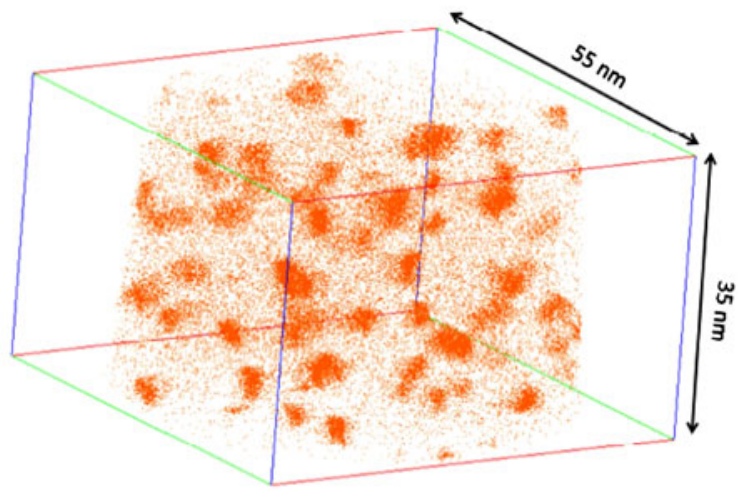

(b)

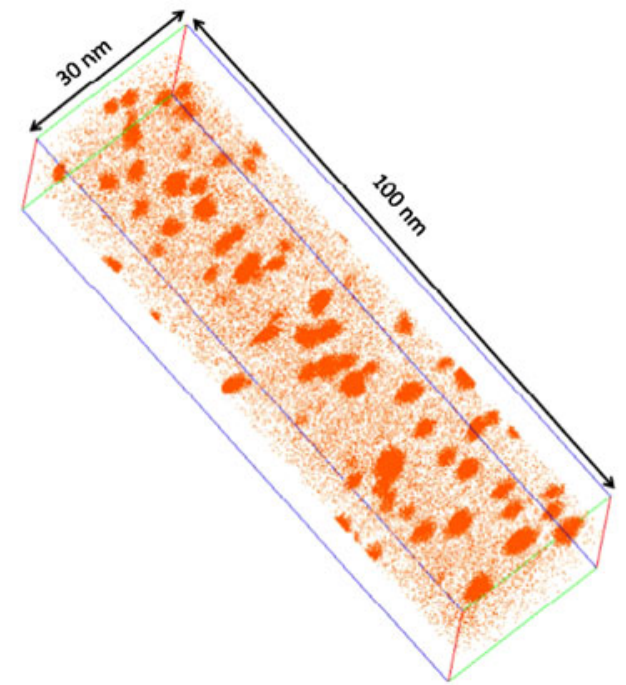

(d)

Fig. 3-3-D LEAP tomographic reconstruction displaying $\mathrm{Cu}$ atoms for $(a)$ coarse-grained HAZ with high heat input, $(b)$ coarse-grained $\mathrm{HAZ}+650$ with high heat input, $(c)$ coarse-grained HAZ with low heat input $(d)$ coarse-grained HAZ +650 with low heat input.

transformation temperature to be approximately $629 \mathrm{~K}$ $\left(356^{\circ} \mathrm{C}\right)$. As expected, no phase transformation was detected during the reheat thermal cycle because the peak temperature $\left(923 \mathrm{~K}\left(650{ }^{\circ} \mathrm{C}\right)\right)$ is lower than $A_{c 1}$. This is indicated by the absence of inflection in the dilatation curve. Vickers microhardness data for these samples are presented in Table III. For single-pass HAZ simulation samples (coarse-grained HAZ with high and low heat input), the microhardness is about $340 \mathrm{HV}$, which is much smaller than that of the as-received base metal, $402 \mathrm{HV}$. For double-pass HAZ samples, the microhardness is approximately $405 \mathrm{HV}$. This result demonstrated that our hypothesis for strength recovery in CGHAZ by double-pass thermal cycles is indeed valid. The magnitude of this recovery is similar to that of samples subjected to PWHT. ${ }^{[5]}$ Although this strength recovery is believed to be the by-product of re-precipitation reactions, it is important to confirm this hypothesis.

\section{B. Microstructure Characterization}

\section{Cu precipitate characterization}

The evolution of $\mathrm{Cu}$-rich precipitates in steels is studied extensively by APT. ${ }^{[9-11]}$ Atomic maps of copper from APT analyses for all samples are summarized in Figure 3. The $\mathrm{Cu}$-enriched regions are not observed in samples subjected only to CGHAZ simulations 
Table IV. Radius and Number Density of Cu Precipitates for As-Received Material and Different Simulated HAZ Regions

\begin{tabular}{|c|c|c|c|c|c|}
\hline & As-Received & $\begin{array}{c}\text { CGHAZ } \\
\text { High Heat } \\
\text { Input }\end{array}$ & $\begin{array}{l}\text { CGHAZ }+650 \\
\text { High Heat Input }\end{array}$ & $\begin{array}{l}\text { CGHAZ Low } \\
\text { Heat Input }\end{array}$ & $\begin{array}{l}\text { CGHAZ }+650 \\
\text { Low Heat Input }\end{array}$ \\
\hline Radius (nm) & $2.4 \pm 1.2$ & $1.7 \pm 0.5$ & $2.4 \pm 1.5$ & $1.9 \pm 1.4$ & $2.6 \pm 1.6$ \\
\hline Number density $\left(10^{23} \mathrm{~m}^{-3}\right)$ & $4.2 \pm 2.2$ & $2.0 \pm 1.1$ & $9.4 \pm 3.1$ & $2.0 \pm 1.4$ & $6.4 \pm 2.5$ \\
\hline
\end{tabular}

Table V. Composition of Martensite Matrix* (Atomic Percent) Measured by Atom Probe

\begin{tabular}{lcccccc}
\hline & $\mathrm{C}$ & $\mathrm{Cr}$ & $\mathrm{Fe}$ & $\mathrm{Ni}$ & $\mathrm{Mo}$ & $\mathrm{Cu}$ \\
\hline CGHAZ high heat input & $0.11 \pm 0.001$ & $1.94 \pm 0.003$ & $87.84 \pm 0.007$ & $6.73 \pm 0.006$ & $0.36 \pm 0.001$ & $2.86 \pm 0.004$ \\
CG HAZ + 650 high heat input & $0.05 \pm 0.001$ & $1.98 \pm 0.007$ & $90.28 \pm 0.015$ & $6.43 \pm 0.012$ & $0.38 \pm 0.003$ & $0.85 \pm 0.004$ \\
CGHAZ low heat input & $0.37 \pm 0.003$ & $1.95 \pm 0.006$ & $86.33 \pm 0.016$ & $7.82 \pm 0.012$ & $0.48 \pm 0.003$ & $2.95 \pm 0.008$ \\
CGHAZ + 650 low heat input & $0.16 \pm 0.002$ & $2.15 \pm 0.008$ & $89.45 \pm 0.017$ & $6.73 \pm 0.014$ & $0.37 \pm 0.003$ & $0.90 \pm 0.005$ \\
\hline
\end{tabular}

*Due to the envelop method used in this analyses, the martensite matrix may contain a small amount of metal carbide and retained austenite.

(Figures 3(a) and (c)). The $\mathrm{Cu}$ atoms are homogenously distributed for both the high and low heat-input conditions. In contrast, the $\mathrm{Cu}$-rich precipitates are clearly seen in the samples subjected to a second thermal cycling (Figures 3(b) and (d)). To obtain quantitative information about the $\mathrm{Cu}$-rich precipitates, a clustersearch algorithm (envelope method) was employed. ${ }^{[8]}$ The following parameters were used: (1) maximum $\mathrm{Cu}$ atom separation $=0.6 \mathrm{~nm},(2)$ minimum number of $\mathrm{Cu}$ atoms in a cluster $=30$, and (3) grid resolution $=0.12 \mathrm{~nm}$. The sensitivity of the parameters is discussed in Reference 1 . The number density, $N_{v}$, is calculated using

$$
N_{v}=\frac{N p \varsigma}{n \Omega}
$$

where $N_{p}$ and $n$ are the number of precipitates and the total number of atoms detected in the volume, respectively; $\Omega$ is the average atomic volume, $1.2 \times 10^{-29} \mathrm{~m}^{-3}$ for bcc $\mathrm{Cu}$; and $\mathrm{X}$ is the detection efficiency of the microchannel plate detector, which is taken to be 0.5 . The summary of the results for the $\mathrm{Cu}$ precipitates is given in Table IV. $\mathrm{Cu}$ precipitates found using the envelope method are extracted and the rest of the atoms are considered as martensite matrix (may contain small amounts of metal carbide and retained austenite). Table $\mathrm{V}$ shows the composition of the martensite matrix.

Even though $\mathrm{Cu}$-enriched regions cannot be seen in the CGHAZ for both high heat input and low heat input, $\mathrm{Cu}$ precipitates with small radii are still detected by the cluster search algorithm. We note that the size and number density of $\mathrm{Cu}$ precipitates are strongly correlated with the parameters chosen for the algorithm. ${ }^{[12]}$ The small precipitates with average radius of $1.7 \mathrm{~nm}$ in the CGHAZ could represent artifacts produced using the cluster search algorithm. The emphasis of this study, however, is to compare the characteristics of $\mathrm{Cu}$ precipitates between a single thermal-cycle HAZ and double thermal-cycle HAZ. The absolute properties of $\mathrm{Cu}$ precipitates are considered to be of secondary importance.

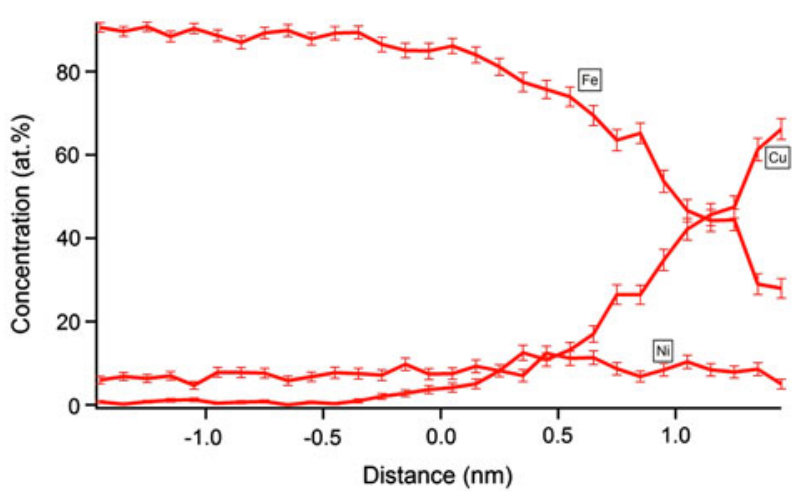

(a)

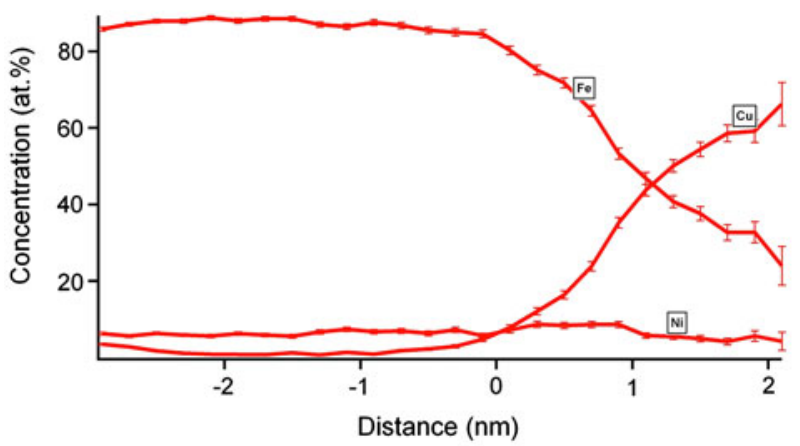

(b)

Fig. 4-Major alloy element composition profile across the copper precipitates boundary in $(a)$ coarse-grained HAZ +650 with high heat input and $(b)$ coarse-grained HAZ +650 with low heat input.

The average radius and number density of $\mathrm{Cu}$ precipitates in heat-treated BlastAlloy 160 are $2.4 \mathrm{~nm}$ and $4.2 \times 10^{23} \mathrm{~m}^{-3}$, respectively. The radius and number density of $\mathrm{Cu}$ precipitates for single-pass CGHAZ in Table IV indicate almost full dissolution of $\mathrm{Cu}$ precipitates. Compared with single-pass CGHAZ, double-pass HAZ samples contain larger $\mathrm{Cu}$ precipitates and higher number density. These $\mathrm{Cu}$ precipitates should have formed within the martensite matrix during the second thermal cycle. Besides the precipitation reaction, the $\mathrm{Cu}$ 


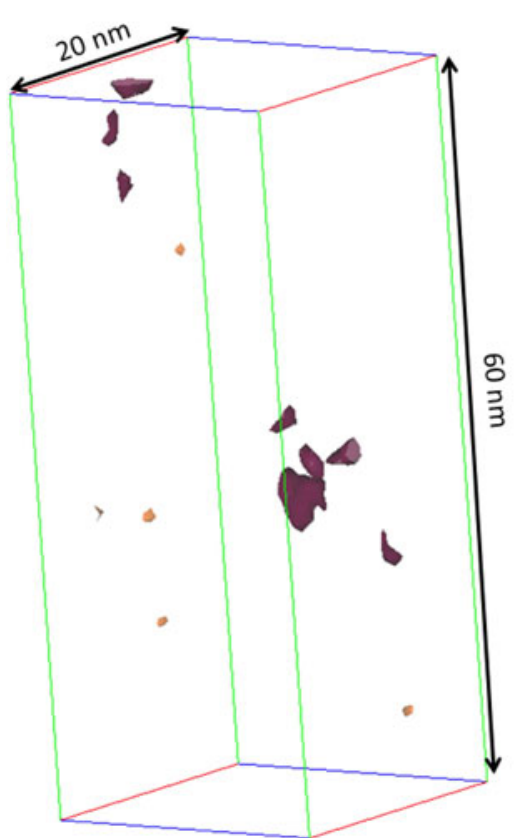

(a)

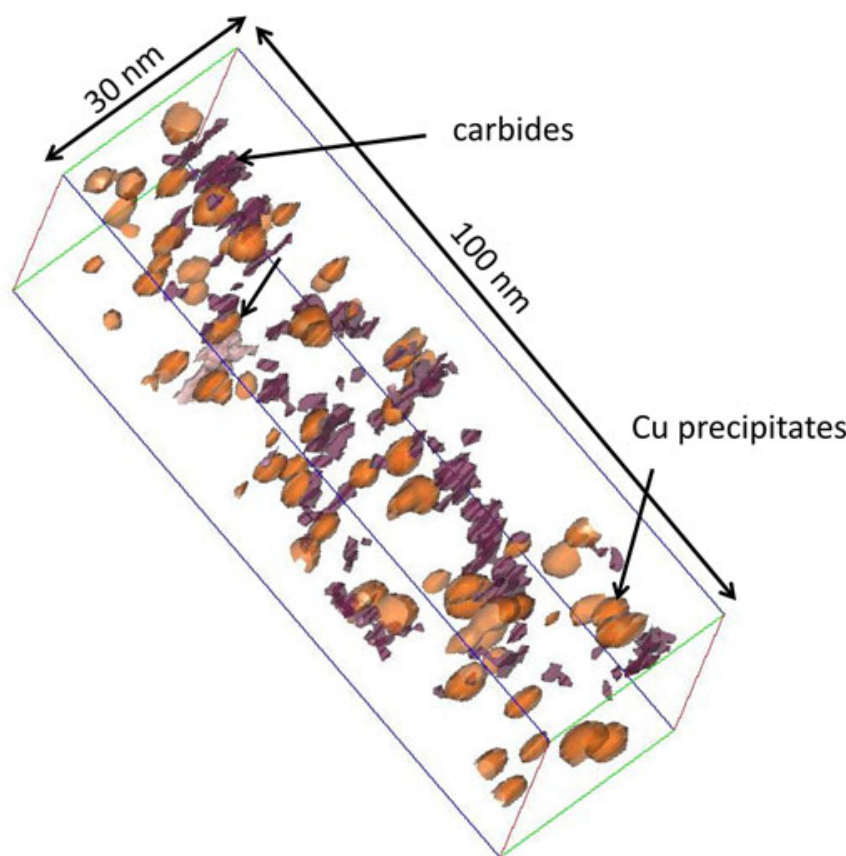

(b)
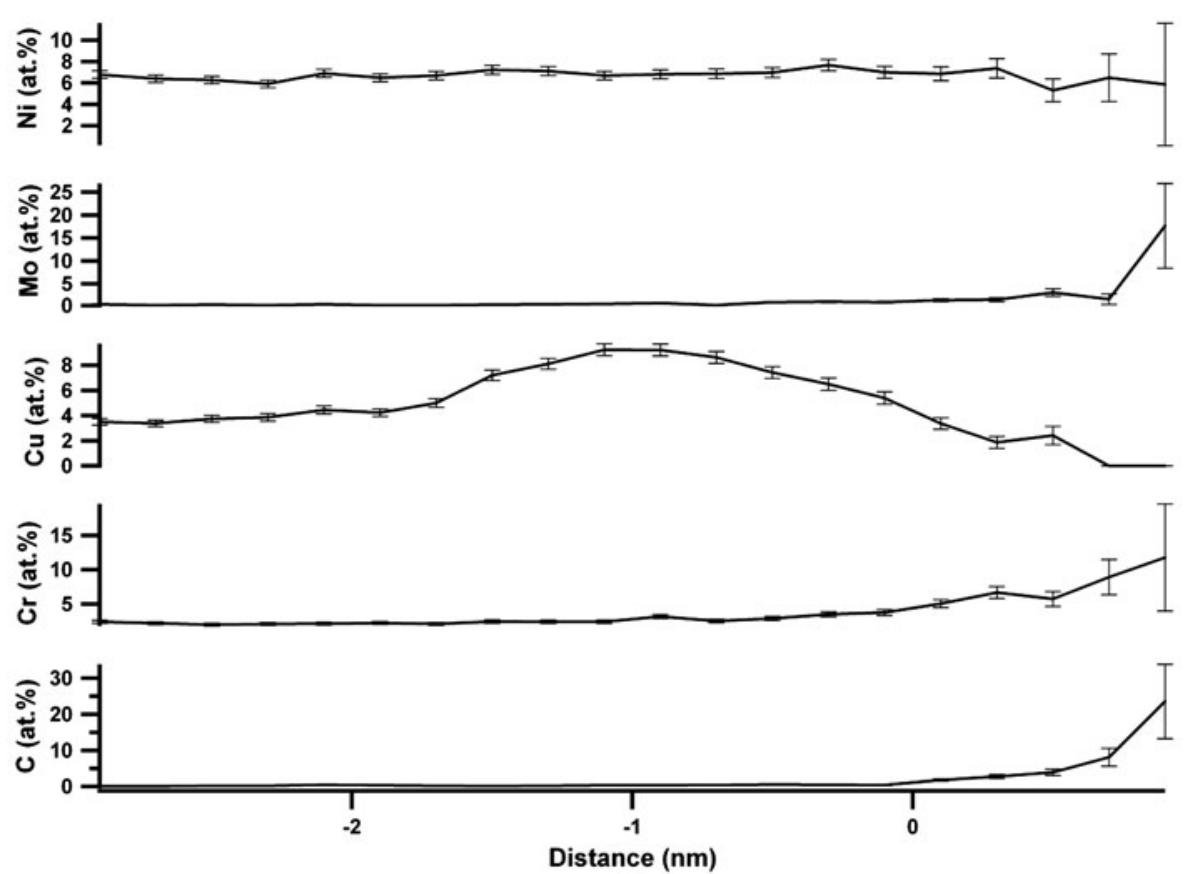

(c)

Fig. 5-1 pct carbon (plum) and 8 pct copper (golden) isoconcentration surface from $(a)$ coarse-grained HAZ with high heat-input sample and $(b)$ coarse-grained HAZ +650 with high heat-input sample. $(c)$ Composition profile across the metal carbide boundary shown by the arrow in (a).

concentration in the martensitic matrix decreases from 2.86 to 0.85 at. pct after the second thermal cycle for high heat-input condition (Table V). The preceding result confirms that the re-precipitation reaction occurred during the second thermal cycle.

To evaluate the strengthening caused by these precipitates, the elemental composition within the precipitates and at the matrix/precipitate interfaces has to be characterized. Proxigram concentration profiles $^{[13]}$ of iron, nickel, and copper across one representative precipitate (CGHAZ + 650 with high heat-input and low heat-input samples) are displayed in Figure 4. The copper concentration in the precipitate core is about 66 at. pct. This concentration is smaller than that of the core concentration in precipitates for the peak-aged condition (>90 at. pct). ${ }^{14]}$ 


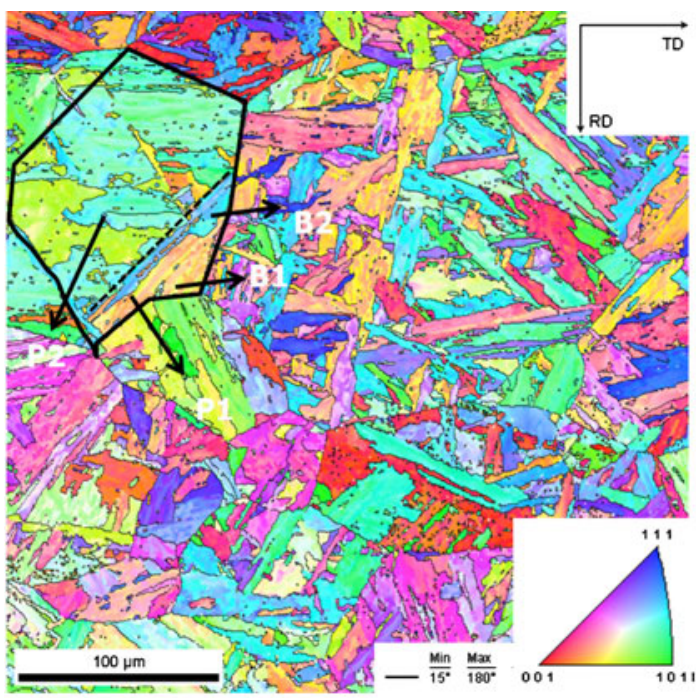

(a)

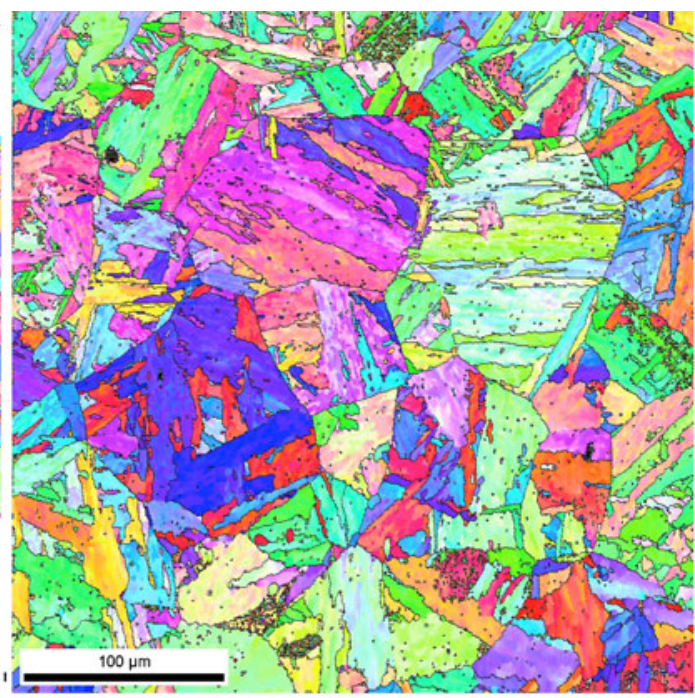

(b)

Fig. 6-Measured EBSD images from (a) coarse-grained HAZ with high heat input and (b) coarse-grained HAZ with low heat input.

Table VI. Packet Size, Block Width, Slip-Plane Length, and for Different HAZ Regions

\begin{tabular}{lccr}
\hline Condition & Packet Size, $d_{p}(\mu \mathrm{m})$ & Block Width, $d_{b}(\mu \mathrm{m})$ & Slip Plane Length, $M(\mu \mathrm{m})$ \\
\hline CGHAZ high heat input & $56.0 \pm 7.5$ & $12.4 \pm 3.5$ & $25.3 \pm 5.0$ \\
CGHAZ + 650 high heat input & $56.0 \pm 7.5$ & $12.4 \pm 3.5$ & $25.3 \pm 5.0$ \\
CGHAZ low heat input & $52.3 \pm 7.2$ & $11.9 \pm 3.4$ & $24.0 \pm 4.9$ \\
CGHAZ + 650 low heat input & $52.3 \pm 7.2$ & $11.9 \pm 3.4$ & $24.0 \pm 4.9$ \\
\hline
\end{tabular}

Both iso-concentration surfaces corresponding to 1 at. pet $\mathrm{C}$ and 8 at. pet $\mathrm{Cu}$ for CGHAZ and CGHAZ + 650 with high heat input are displayed in Figure 5. Only faint precipitate-like features could be visualized in the data from CGHAZ. In contrast, the iso-concentration surfaces from the CGHAZ +650 high heat-input sample (Figure 5(b)) revealed copious $\mathrm{Cu}$ precipitates and metal carbides. One of the precipitates was selected for further analysis (indicated by the bold arrow in Figure 5(b)). Proxigram concentration profiles across the metal carbide interface are plotted in Figure 5(c). The metal carbide is enriched with $\mathrm{Cr}$ and Mo. Since the $\mathrm{C}$ concentration in the core of the carbide precipitates is approximately 30 at. pct, this metal carbide is most likely $\mathrm{M}_{2} \mathrm{C}$ type (where $\mathrm{M}=\mathrm{Fe}, \mathrm{Cr}$, Mo). The $\mathrm{Cu}$ is depleted within the carbide precipitate and enriched near the carbide/martensite interface. This observation supports the published report of co-location of $\mathrm{Cu}$ precipitates and $\mathrm{Mo} / \mathrm{Cr}$-enriched metal carbide ${ }^{[14]}$ for the peak-aged condition.

\section{Martensite Substructure}

Previous study on HAZ properties of BA160 found, besides $\mathrm{Cu}$ precipitate strengthening, that martensite substructure plays an important role in strengthening. ${ }^{[6]}$ Fine martensite substructure contributes to the hardening in the ICHAZ. The current investigation also employed the EBSD technique to study the morphology and crystallography of the martensitic matrix. The martensite substructure of a single-pass BA160 HAZ was reported. ${ }^{\uparrow[6]}$ Two EBSD maps of CGHAZ with high

\footnotetext{
"There is a typographical error in Ref. 5 regarding to slip plane length of coarse-grained HAZ. In this article it is reported as $2.53 \mu \mathrm{m}$. The correct slip plane length for coarse-grained HAZ is $25.3 \mu \mathrm{m}$.
}

heat input and low heat input are shown in Figure 6. Since dilatation measurements showed no reverse transformation (martensite to austenite) during the second thermal cycle, martensite morphology is assumed similar to that of CGHAZ samples. Therefore, the martensite substructures in CGHAZ + 650 high heat-input and CGHAZ + 650 low heat-input samples were not measured. The characteristics of the martensite substructure are summarized in Table VI.

\section{DISCUSSION}

\section{A. Precipitate Evolution in Heat-Affected Zone}

APT results show re-precipitation of $\mathrm{Cu}$ and metal carbide precipitates during the second heat treatment of the double pass HAZ. In the HAZ of BA160, the solidstate transformations are complex due to on-heating transformation of martensite to austenite, precipitate growth and coarsening, precipitate dissolution, reformation of precipitates during cooling, and on-cooling transformation of austenite to martensite. A schematic 
illustration of phase transformation stages ${ }^{[6]}$ in the CGHAZ sample is shown in Figure 7. The $\mathrm{Cu}$ solid solubility in austenite and ferrite, evaluated with THERMO-CALC ${ }^{\text {बथ }}$ software using the TCFE5

${ }^{\top}$ THERMO-CALC is a trademark of Thermo-Calc, Stockholm.

thermodynamic database, is also shown in Figure $7 .{ }^{[15]}$ During the first CGHAZ thermal cycle, when the material is heated from $\mathrm{P} 1$ to $\mathrm{P} 4$, martensite transforms to austenite and all precipitates dissolve in the austenite matrix. On cooling from P4 to P5, due to the high solubility of $\mathrm{Cu}$ and $\mathrm{C}$ in austenite and a short cooling period, re-precipitation is limited. Below $M_{s}$, precipitation is not expected because the diffusivities of $\mathrm{Cu}$ and $\mathrm{C}$ are small. During the second thermal cycle, on heating to a temperature below $A_{c 1}$, the nucleation and growth of $\mathrm{Cu}$ and metal carbide precipitates is expected within the martensite matrix. Figure 7 (a) shows that the solubility of $\mathrm{Cu}$ in ferrite at $923 \mathrm{~K}\left(650^{\circ} \mathrm{C}\right)$ is about 0.7 at. pct. Since the $\mathrm{Cu}$ concentration in the material is 3.3 at. pct, $\mathrm{Cu}$ is still supersaturated at this temperature. High $\mathrm{Cu}$ diffusivity and supersaturation of $\mathrm{Cu}$ promote the nucleation and growth of $\mathrm{Cu}$ precipitates.

Most $\mathrm{Cu}$-bearing steel studies are focused on isothermal aging. Only limited articles report $\mathrm{Cu}$ evolution during nonisothermal conditions. It is well known that during aging of $\mathrm{Fe}-\mathrm{Cu}$ or $\mathrm{Fe}-\mathrm{Cu}-\mathrm{Ni}$ alloys, the transformation sequence for $\mathrm{Cu}$ precipitates is bcc $\rightarrow 9 \mathrm{R} \rightarrow$ $3 \mathrm{R} \rightarrow \mathrm{fcc}$ with increasing aging time. However, the kinetics of $\mathrm{Cu}$ precipitate evolution is slow. During

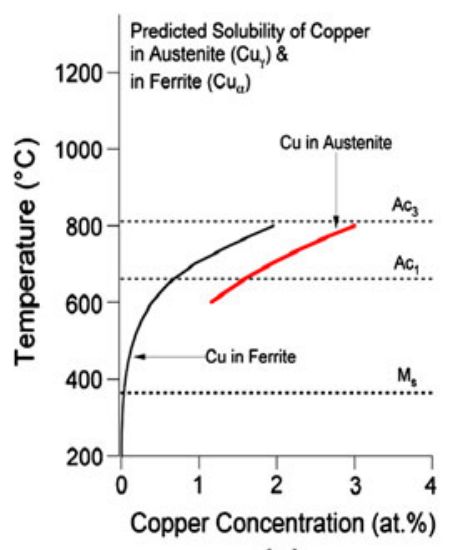

(a)

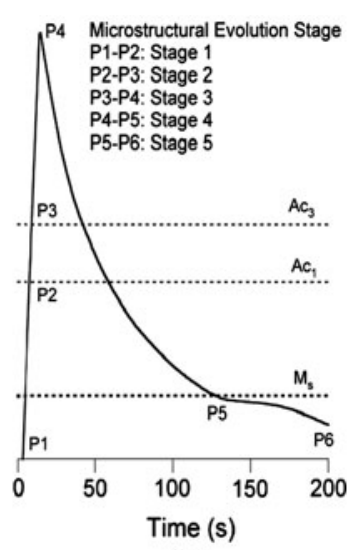

(b)
Fig. 7-(a) Predicted solubility of $\mathrm{Cu}$ in austenite and ferrite is displayed as a function of temperature. (b) Schematic illustration of different stages in microstructure evolution in coarse-grained HAZ region. ${ }^{[6]}$ welding, the HAZ only experiences a short period of heating, which is not enough to bring the $\mathrm{Cu}$ precipitate to overage condition. The single thermal cycle HAZ simulation confirmed no significant overaging in simulated HAZ even when the peak temperature is higher than $A_{c 1}$. In multipass HAZ, however, if the peak temperature of a subsequent pass is higher than $A_{c 3}$, the dissolution of precipitates is expected and strength loss will occur. The welding procedure of BA160 is still under development, and detailed thermal histories in multipass HAZs are not available. Therefore, the precipitations after many $(>2)$ thermal cycles are not discussed here. By comparing the results between high heat input and low heat input, one can conclude that precipitation is not sensitive to heat input. In samples subjected to both high and low heat-input conditions, atom probe results show similar $\mathrm{Cu}$ precipitate sizes and number densities. This again suggests that the welding procedure window for BA160 may be wide and conducive to field welding conditions.

\section{B. Modeling of Strengthening Mechanism}

A previous study ${ }^{[6]}$ proposed a strengthening model by considering $\mathrm{Cu}$ precipitation and martensite substructure strengthening to interpret the hardening and softening phenomena in a simulated HAZ of BA160 (Appendix). However, due to the dissolution of metal carbide, this strengthening model for a single-pass HAZ did not consider the metal carbide contribution. Since metal carbides reprecipitate during the second thermal cycle, the strengthening contribution from metal carbide precipitates should be taken into account. Precipitates are bypassed by the Orowan dislocation looping mechanism, which is dominant for hard precipitates in soft

Table VIII. Strengthening Contributions in Different HAZ Samples $\left(\sigma_{p}\right.$-Strengthening by $\mathrm{Cu}$ Precipitates, $\sigma_{g}$-Strengthening by Martensite Lath Boundaries, $\sigma_{c}$-Strengthening by Metal Carbides, and $\Delta_{\sigma}$-Overall Strengthening)

\begin{tabular}{lrrrr}
\hline Condition & $\begin{array}{c}\sigma_{p} \\
(\mathrm{MPa})\end{array}$ & $\begin{array}{c}\sigma_{g} \\
(\mathrm{MPa})\end{array}$ & $\begin{array}{c}\sigma_{c} \\
(\mathrm{MPa})\end{array}$ & $\begin{array}{r}\Delta \sigma \\
(\mathrm{MPa})\end{array}$ \\
\hline SCHAZ high heat input & 282.5 & 127.0 & 0.0 & 409.5 \\
ICHAZ high heat input & 190.0 & 290.0 & 0.0 & 480.0 \\
FGHAZ high heat input & 4.8 & 213.0 & 0.0 & 217.8 \\
CGHAZ high heat input & 15.8 & 72.3 & 0.0 & 88.1 \\
CGHAZ low heat input & 57.3 & 74.1 & 0.0 & 131.4 \\
$\begin{array}{l}\text { CGHAZ + 650 high } \\
\text { heat input }\end{array}$ & 182.5 & 72.3 & 110.9 & 365.7 \\
$\begin{array}{l}\text { CGHAZ + 650 low } \\
\text { heat input }\end{array}$ & 176.0 & 74.1 & 105.3 & 355.4 \\
\hline
\end{tabular}

Table VII. Radius and Number Density of M2C Precipitates for As-Received Material and Different HAZ Regions

\begin{tabular}{lcccc}
\hline & $\begin{array}{c}\text { CGHAZ High } \\
\text { Heat Input }\end{array}$ & $\begin{array}{c}\text { CGHAZ + 650 } \\
\text { High Heat Input }\end{array}$ & $\begin{array}{c}\text { CGHAZ Low } \\
\text { Heat Input }\end{array}$ & $\begin{array}{c}\text { CGHAZ + 650 } \\
\text { Low Heat Input }\end{array}$ \\
\hline Radius (nm) & 0 & $1.23 \pm 1.1$ & 0 & $1.19 \pm 0.7$ \\
Volume fraction & 0 & 0.00023 & 0 & 0.00020 \\
\hline
\end{tabular}




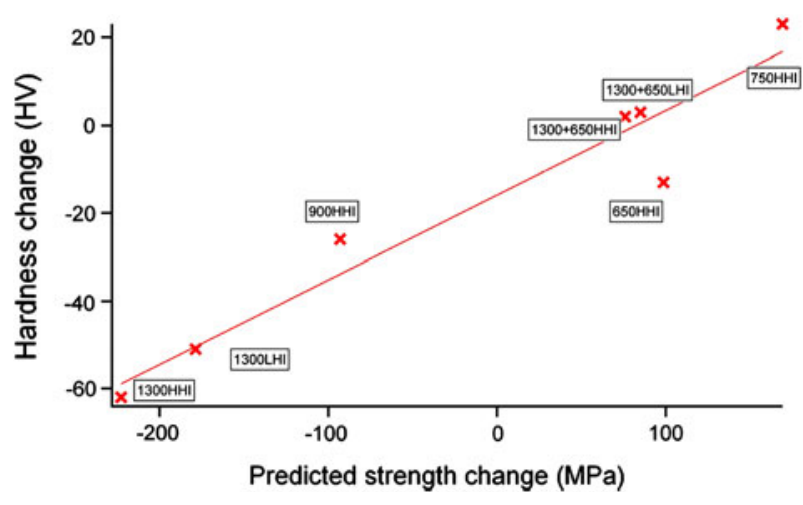

Fig. 8-Predicted strength increase due to martensite substructure and copper precipitates compared with experimentally measured microhardness changes in the HAZ regions.

matrix. ${ }^{[16,17]}$ In this article, the Orowan hardening mechanism is used to predict the contribution of metal carbide to the overall strengthening. The OrowanAshby ${ }^{[18]}$ equation for looping of dislocations between precipitates is given by

$$
\tau_{c}=\frac{0.81 G \mathbf{b}}{2 \pi(1-v)^{2} L} \ln \left(\frac{2 r^{\prime}}{\mathbf{b}}\right)
$$

where $\tau_{c}$ is the resolved shear strength increase due to the metal carbide, $G$ is the shear modulus ( $77 \mathrm{GPa}), v$ is Poisson's ratio (0.3), $L$ is the effective interprecipitate spacing, ${ }^{[6]} r^{\prime}$ is the mean precipitate radius, and $\mathbf{b}$ is the Burger's vector of a dislocation $(0.25 \mathrm{~nm})$. The properties of metal carbides can be estimated from the APT analysis results listed in Table VII.

By inputting characteristics of the martensite, $\mathrm{Cu}$ precipitates, and metal carbides into the strengthening model, the total strengthening contributions can be calculated (Table VIII). Data from the single-pass $\mathrm{HAZ}^{[6]}$ is also included to evaluate current strengthening models. The predicted strength change is plotted as a function of observed microhardness change (Figure 8) for all HAZ regions. In these calculations, the base metal microhardness is used as a reference. A near linear relationship between the predicted strength difference and microhardness difference suggests a validation of the strength model proposed here.

\section{Suggestions for Modified Heat Treatment of BA160 Steel}

Most of the research on $\mathrm{Cu}$ precipitate-strengthened steels has focused on isothermal aging treatments. ${ }^{[19-21]}$ The aging times are typically from 0.5 to 320 hours. These aging treatments are long and energy consuming. This study suggests an alternative path forward for $\mathrm{Cu}$ precipitation in BA160 using a rapid aging treatment. This rapid heat treatment involves traditional austenitizing (Table II) and quenching to liquid nitrogen temperature $\left(78 \mathrm{~K}\left(-195^{\circ} \mathrm{C}\right)\right)$ followed by rapid heating of $373 \mathrm{~K}\left(100{ }^{\circ} \mathrm{C}\right)$ per second to $923 \mathrm{~K}\left(650^{\circ} \mathrm{C}\right)$. Optimization of these nonisothermal heat treatments will require detailed kinetic modeling.

\section{CONCLUSIONS}

The softening in the CGHAZ region of BA 160 is partly attributed to the dissolution of $\mathrm{Cu}$ and metal carbide precipitates.

Recovery of strength during multipass welding was demonstrated through two-cycle thermal simulations. During the first cycle, on heating the steel above $A_{c 3}$, softening was observed due to precipitate dissolution. During the second thermal cycle, on heating the steel below $A_{c 1}$, re-precipitation of copper precipitates and carbides was promoted. This leads to an increase in hardness from 340 to $405 \mathrm{HV}$.

A strength model, including precipitation and martensite substructure strengthening, describes the observed softening and hardening in the HAZ simulated samples.

The current study also suggests a rapid nonisothermal aging treatment (heating rate $=100{ }^{\circ} \mathrm{C} / \mathrm{s}$ and peak temperature $\left.=923 \mathrm{~K}\left(650^{\circ} \mathrm{C}\right)\right)$ for strengthening of the original BA160 steel, instead of long isothermal aging treatments.

\section{ACKNOWLEDGMENTS}

We acknowledge financial support from the Office of Naval Research, Drs. J. Christodoulou and W. Mullins, grant monitors. Atom-probe tomographic measurements were performed at the Northwestern University Center for Atom-Probe Tomography (NUCAPT). The authors also thank Professor G. Olson, Northwestern University, for providing the samples. The LEAP tomograph was purchased and upgraded with funding from NSF-MRI (Grant No. DMR-0420532) and ONR-DURIP (Grant Nos. N00014-0400798, N00014-0610539, and N000140910781).

\section{APPENDIX}

\section{Modeling of Strengthening Mechanisms}

For martensitic strengthening, the yield stress of the lath martensite is calculated by summing the contributions from different hardening mechanisms: ${ }^{[22]}$

$$
\sigma_{Y S}=\sigma_{0}+\sigma_{s}+\sigma_{\rho}++\sigma_{g}+\sigma_{P}
$$

where $\sigma_{0}$ is the friction stress to move dislocations for pure $\mathrm{Fe}, \sigma_{s}$ is the yield strength increment due to solidsolution hardening, $\sigma_{\rho}$ is the strengthening term due to the forest dislocation density, $\sigma_{g}$ is for grain-boundary strengthening, and $\sigma_{p}$ is for precipitate strengthening. For the four mechanisms, $\mathrm{Cu}$ is the major element varied in the matrix. According to Reference 23, the yield strength increment due to $1 \mathrm{wt}$ pet $\mathrm{Cu}$ in solid solution is $<50 \mathrm{MPa}$. Additionally, the dislocation density is a function of $M_{s}$ and the variation of $M_{s}$ in different HAZ regions is small. ${ }^{[6]}$ On the other hand, the strengthening contribution on yield strength from $\mathrm{Cu}$ 
precipitates and martensite block and packet boundaries could be several hundred mega-Pascals. ${ }^{[1,22]}$ As a result, in the present study, only precipitation and grain boundary strengthening are considered in the overall strengthening.

\section{Martensite Matrix Strengthening}

The packet size and block width in the different regions of the HAZ were measured from the EBSD maps using the mean linear-intercept method. ${ }^{[24]}$ Most researchers take the contributions from block width and packet size into account separately when considering grain boundary strengthening. ${ }^{[25,26]}$ The two important parameters, packet size and block width, describe the morphology of lath martensite. Since packet and block boundaries are high-angle boundaries ( $>15 \mathrm{deg}$ ), they should be considered together for grain boundary strengthening. Since the block boundaries inside a packet act as obstacles to dislocation motion, the slip plane length can be described to a certain degree by block width and packet size, which is elaborated in the following content. Assuming that the block morphology is rectangular and the length of the block is equivalent to the packet size, the average slip plane length, $M$, can be calculated from the block width, $d_{b}$, and packet size, $d_{p} .{ }^{[25]}$

$$
M=\frac{1}{\pi / 2}\left[\int_{0}^{a \cos \left(d_{b} / d_{p}\right)} \frac{d_{b}}{\cos \theta} d \theta+\int_{a \cos \left(d_{b} / d_{p}\right)}^{\pi / 2} d_{p} d \theta\right]
$$

From the calculated average slip-plane length, the strengthening introduced by block boundaries can be calculated from the Hall-Petch equation:

$$
\sigma_{g}=K_{y} M^{-1 / 2}
$$

where $K_{y}$ is $0.363 \mathrm{MPa} \mathrm{m}^{1 / 2}{ }^{[25]}$

\section{Copper Precipitation Strengthening}

Precipitate shearing and precipitate bypass by dislocation looping are two mechanisms generally used to explain precipitate strengthening. ${ }^{[27,28]} \mathrm{Bcc} \mathrm{Cu}$ precipitates in martensite matrix are considered as weak precipitates. ${ }^{[31]}$ The strength contributions arising from $\mathrm{Cu}$ precipitation are difficult to model. Many factors, such as misfit strengthening, chemical strengthening, modulus difference strengthening, and dislocation coreprecipitate interaction strengthening contribute to the overall $\mathrm{Cu}$ precipitate strengthening in steels. ${ }^{[29]}$ The incorrect equation used to describe modulus difference strengthening by Fine and Isheim ${ }^{[29]}$ has been pointed out by Liu et al. ${ }^{[30]}$ Since modulus strengthening based upon the model of Russell and Brown ${ }^{[31]}$ plays the most important role among all the factors, the current focus is on evaluating the component of $\mathrm{Cu}$ precipitation strengthening provided by modulus strengthening. The Russell-Brown model assumes that the modulus strengthening effect is due to the relative difference in dislocation energy between the matrix and $\mathrm{Cu}$ precipitates as a result of the modulus difference, as a dislocation passes from the matrix through the $\mathrm{Cu}$ precipitate and back into the matrix. The critical shear stress increase caused by the $\mathrm{Cu}$ precipitates can be expressed as

$$
\begin{aligned}
& \tau=0.8 \frac{G \mathbf{b}}{L}\left[1-\frac{E_{P}^{2}}{E_{M}^{2}}\right]^{1 / 2} ; \quad \sin ^{-1} \frac{E_{P}}{E_{M}} \leq 50^{\circ} \\
& \tau=\frac{G \mathbf{b}}{L}\left[1-\frac{E_{P}^{2}}{E_{M}^{2}}\right]^{3 / 4} ; \quad \sin ^{-1} \frac{E_{P}}{E_{M}} \geq 50^{\circ} \\
& \frac{E_{P}}{E_{M}}=\frac{E_{P}^{\infty} \log \frac{r}{r_{0}}}{E_{M}^{\infty} \log \frac{R}{r_{0}}}+\frac{\log \frac{R}{r}}{\log \frac{R}{r_{0}}}
\end{aligned}
$$

where $G$ is the shear modulus in the matrix, taken to be $77 \mathrm{GPa} ; \quad L$ is the interprecipitate spacing; $\mathbf{b}$ is the Burger's vector of dislocation, which is $0.25 \mathrm{~nm} ; E_{P}$ is the dislocation energy in the precipitate; and $E_{M}$ is the dislocation energy per unit length in the matrix. The term $E_{P}^{\infty}$ is the dislocation energy per unit length in the precipitate; $E_{M}^{\infty}$ is the dislocation energy per unit length in the matrix; $r$ is the average radius of the precipitates; $r_{0}$ is the inner cut-off radius, $0.7 \mathrm{~nm}$; and $R$ is the outer cut-off radius, $1000 r_{0}$. It is assumed that the shear modulus for bcc $\mathrm{Cu}$ in the Fe matrix is equivalent to the shear modulus for fcc $\mathrm{Cu}$. For a screw dislocation, the estimated dislocation energy ratio per unit length in an infinite media, $E_{P}^{\infty} / E_{M}^{\infty}$, is equal to the shear modulus ratio $\left(G_{p} / G_{m}\right)$. This study used the bulk shear modulus ratio of fcc $\mathrm{Cu}$ and bcc Fe, which is 0.6 in the calculation. Substituting the precipitate properties obtained from the atom- probe tomographic analysis into the modulus difference (Eq. [A4]), an estimate of the $\mathrm{Cu}$ precipitate strengthening can be provided. It is realized that the Russell-Brown strengthening model is very sensitive to the modulus difference. The measurement of the bcc $\mathrm{Cu}$ shear modulus is complicated, since bcc $\mathrm{Cu}$ in the $\alpha$-Fe matrix is metastable and the lattice parameter of bcc $\mathrm{Cu}$ is very close to that of bcc Fe. Firstprinciple calculations predicted that the tetragonal shear modulus for bec $\mathrm{Cu}$ could be negative ${ }^{[30,32,33]}$ Liu et al. predictions depended on Fe concentration in the precipitate; the shear modulus of bcc $\mathrm{Cu}$ varies from $80 \mathrm{GPa}$ to $-20 \mathrm{GPa}$. If the shear modulus of bcc $\mathrm{Cu}$ is positive, the Russell-Brown modulus-mismatch hardening model could be used as a good estimate for bcc $\mathrm{Cu}$ precipitate strengthening. Harry and Bacon ${ }^{[34]}$ proposed an alternative strengthening mechanism. When the unstable bcc $\mathrm{Cu}$ precipitate is sheared by a dislocation, the bcc $\mathrm{Cu}$ lattice may transform to a close-packed structure. During shearing, strength is increased by the structural-transformation mechanism. This mechanism may be considered for the conditions, which leads to a negative shear modulus of bcc $\mathrm{Cu}$. Since the shear modulus of bcc $\mathrm{Cu}$ and the strengthening mechanism are still being debated, this study applies the classic RussellBrown model and the parameters to estimate the strengthening by $\mathrm{Cu}$ precipitates. We note that the model could be improved if an accurate bcc $\mathrm{Cu}$ shear modulus and effective interprecipitate distance could be estimated. This will require in-situ measurement of the $\mathrm{Cu}$ precipitate modulus using in-situ diffraction techniques. ${ }^{35]}$ 


\section{REFERENCES}

1. A. Saha and G.B. Olson: J. Comput. Aided Mater. Des., 2007, vol. 14 , pp. 177-200.

2. A. Saha and G.B. Olson: J. Comput. Aided Mater. Des., 2007, vol. 14 , pp. 201-33.

3. E.J. Czyryca, D.P. Kihl, and R. DeNale: AMPTIAC Q, 2003 , vol. 7 (3), pp. 63-70.

4. R.D. Campbell and D.W. Walsh: ASM Handbook, ASM, Material Park, OH, 1993, vol. 6, pp. 603-13.

5. C. Jeremy: Ph.D. Thesis, The Ohio State University, Columbus, $\mathrm{OH}, 2010$

6. X. Yu, J.L. Caron, S.S. Babu, J.C. Lippold, D. Isheim, and D.N. Seidman: Acta Mater., 2010, vol. 58, pp. 5596-5609.

7. ASTM E-384-08, ASTM, Philadelphia, PA, 2008

8. M.K. Miller: Atom Probe Tomography, Kluwer Academic/Plenum Publishers, New York, NY, 2000.

9. D. Isheim, R.P. Kolli, M.E. Fine, and D.N. Seidman: Scripta Mater., 2006, vol. 55, pp. 35-40.

10. R.P. Kolli, R.M. Wojes, S. Zaucha, and D.N. Seidman: Int. J. Mater. Res., 2008, vol. 99, pp. 513-27.

11. R.P. Kolli and D.N. Seidman: Acta Mater., 2008, vol. 56, pp. 2073-88.

12. R.P. Kolli and D.N. Seidman: Microsc. Microanal., 2007, vol. 13, pp. $272-84$

13. O.C. Hellman, J.A. Vandenbroucke, J. Rusing, D. Isheim, and D.N. Seidman: Microsc. Microanal., 2000, vol. 6, pp. 437-44.

14. M. Mulholland and D.N. Seidman: Scripta Mater., 2009, vol. 60, pp. 992-95.

15. J.O. Andersson et al.: CALPHAD, 2002, vol. 26, pp. 273-312.

16. C.B. Fuller, D.N. Seidman, and D.C. Dunand: Acta Mater., 2003, vol. 51, pp. 4803-14.

17. D.N. Seidman, E.A. Marquis, and D.C. Dunand: Acta Mater. 2002, vol. 50, pp. 4021-35.
18. J.H. Beatty and G.J. Shiflet: Metall. Trans. A, 1988, vol. 19A, pp. $1617-20$

19. R. Monzen, M.L. Jenkins, and A.P. Sutton: Philos. Mag. A, 2000, vol. 80 , pp. 711-23

20. N. Maruyama, M. Sugiyama, T. Hara, and H. Tamehiro: JIM, 1999, vol. 40, pp. 268-77.

21. D. Isheim, M.E. Fine, and D.N. Seidman: Microsc. Microanal., 2007, vol. 13, pp. 1624-25.

22. S. Morito and T. Ohba: Proc. 1st Int. Symp. on Steel Sci., 2007, pp. $57-62$

23. J. Syarif, T. Tsuchiyama, and S. Takaki: ISIJ Int., 2003, vol. 7, pp. $1100-04$

24. A. Thorvaldsen: Acta Mater., 1997, vol. 45, pp. 595-600.

25. J.P. Naylor: Metall. Trans. A, 1979, vol. 10A, pp. 861-73.

26. S. Morito, H. Yoshida, T. Maki, and X. Huang: Mater. Sci. Eng. $A$, 2006, vols. 438-440, pp. 237-40.

27. E. Nembach: Particle Strengthening of Metals and Alloys, John Wiley \& Sons, New York, NY, 1997.

28. A.S. Argon: Strengthening Mechanisms in Crystal Plasticity, Oxford University Press, New York, NY, 2008.

29. M.E. Fine and D. Isheim: Scripta Mater., 2005, vol. 53, pp. 115 18

30. J.Z. Liu, A. Van de Walle, G. Ghosh, and M. Asta: Phys. Rev. B, 2005, vol. 72, p. 144109.

31. K.C. Russell and L.M. Brown: Acta Metall., 1972, vol. 20, pp. 969-74.

32. P.J. Craievich, N. Weinert, J.M. Sanchez, and R.E. Watson: Phys. Rev. Lett., 1994, vol. 72, pp. 3076-79.

33. L.G. Wang, M. Sob, and Z. Zhang: J. Phys. Chem. Solids, 2003, vol. 64 , pp. $863-72$

34. T. Harry and D.J. Bacon: Acta Mater., 2002, vol. 50, pp. 195208

35. S.S. Babu: Int. Mater. Rev., 2009, vol. 54, pp. 333-36. 